\title{
Casa de ferreiro, espeto de pau: o tabagismo entre profissionais de saúde
}

The shoemaker's son always goes barefoot: smoking among healthcare professionals

SMITH, Derek R.; LEGGAT, Peter A. Smoking among healthcare professionals. Sydney, Australia: Darlington Press, 2011. 104p. ISBN: 9781921364174

A Organização Mundial de Saúde (OMS) atribui cinco milhões de mortes ao ano em todo o mundo às doenças relacionadas ao tabagismo (EZZATI, 2003). Caso persistam os padrões atuais de consumo, estima-se que, por volta de 2030, o tabaco cause 10 milhões de mortes anuais (IGLESIAS et al., 2007).

No Brasil, as políticas que inibem o uso do tabaco articulam medidas coercitivas como as leis anti-fumo (proíbem o tabagismo em espaços coletivos fechados), adotam restrições à publicidade e propaganda, exigem a impressão de advertências nas embalagens de cigarros, limitam os teores de nicotina, alcatrão e monóxido de carbono e ofertam tratamento na rede pública de saúde para os usuários. Aparentemente, estas ações foram responsáveis pela redução da proporção de fumantes na população de 34,8\% em 1998 para 15,1\% em 2010 (BRASIL, 2011).

Há publicações que apontam maior prevalência de tabagismo entre indivíduos com menor nível de escolaridade e de renda e inserção no mercado de trabalho em atividades menos qualificadas, indicando associações entre trabalho e tabagismo (BAYER; STUBER, 2006; BARBEAU; KRIEGER; SOOBADER, 2004; MONTEIRO et al., 2007; INSTITUTO NACIONAL DE CÂNCER, 2004). No Brasil, Giatti e Barreto (2011) verificaram que estar inserido no trabalho sem proteção social e estar desempregado está associado à maior prevalência de tabagismo, independentemente da escolaridade. Estes achados tornam ainda mais instigante o livro de Derek Smith, professor de Saúde Ocupacional e Ambiental na Universidade de Newcastle e, Peter Leggat professor de Saúde Pública na James Cook University, ambas na Austrália.

O livro trata do desafio de redução do tabagismo entre profissionais da área de saúde, traçando um panorama da prevalência do hábito tabágico em vários países. Em seu prefácio (Foreword) os autores defendem a importância dos profissionais de saúde na luta anti-tabágica pelas oportunidades que o contato com os pacientes oferece de diagnóstico das doenças relacionadas ao tabaco e educação para a saúde, e por serem considerados 'modelo' de estilo de vida saudável, influenciando comportamen- tos individuais e coletivos. $\mathrm{O}$ fato de adotarem um comportamento não saudável leva a uma incongruência de comportamentos e ao desencontro entre o que o profissional faz e o que ele preconiza. Este antagonismo reduz a disposição dos pacientes em aderir às recomendações médicas relativas à interrupção do hábito e, reduz a disposição do próprio profissional que fuma em abordar o paciente sobre o hábito (MAECKELBERGHE, 2013). Outros autores sugerem que, muitas vezes, trabalhadores da saúde consideram o combate ao tabagismo importante, mas não uma prioridade em termos de plano terapêutico, além de não conseguirem se posicionar como agentes de promoção à saúde (CATTARUZZA; WEST, 2013).

Após a introdução (Introduction), onde os autores explicitam de forma sumária o conteúdo do livro, o segundo Capítulo (Methodology) descreve as estratégias de busca dos estudos e as bases de dados utilizadas, os critérios de inclusão e de exclusão dos artigos, e as limitações inerentes à literatura consultada, com destaque para a taxa de resposta sub ótima de muitos inquéritos, a falta de um padrão do que seja fumante atual, a escassez de estudos de países em desenvolvimento e a falta de especificação de qual o produto fumado.

O Capítulo 3 (Tobbaco use among health care professionals) é o capítulo central do livro e revê a literatura existente sobre profissionais da área de medicina, odontologia e enfermagem. Muito embora exista uma tendência global de declínio do hábito ao longo dos últimos 30 anos, as taxas ainda são bastante altas em alguns países, como na Grécia no caso dos médicos (39\%), os odontólogos no Brasil (37\%) e na Itália, Espanha e Reino Unido entre os profissionais de enfermagem (percentuais entre 29\% a 50\%). Estas variações dificultam o entendimento da relação causal comum entre tabagismo e trabalho no setor saúde. Para os autores os grupos profissionais pesquisados subestimam a sua capacidade de influência sobre o hábito tabágico dos pacientes, especialmente os odontólogos. Contudo, estudo no Brasil já indica que há formas claras por meio das quais o Odontólogo do Trabalho pode agir no acon- 
selhamento visando ao combate do tabagismo entre os as pessoas em seus locais de trabalho (AZNAR; PERES; PERES, 2012).

O Capítulo 4 (Tobacco use among healthcare students) teve como base estudos que revelaram que países da Europa Oriental tiveram as taxas mais altas de prevalências: Albânia destacou-se com 43\%, chegando a $65 \%$ entre os estudantes de medicina. Intrigante é o aumento do uso do tabaco entre os universitários com o avanço nos anos de universidade. A questão é controversa e sofre efeito da idade; além disso, poucos estudos comparam estudantes de graduação com aqueles de pós-graduação. No Brasil, estudos recentes indicam que a prevalência de hábito tabágico e tabagismo ocasional entre estudantes da área de saúde é preocupante (SZKLO et al., 2011).

O quinto Capítulo (Success stories in declining tobacco use) descreve a evolução nas taxas de uso habitual de tabaco entre médicos australianos e norte-americanos. Muito embora os resultados para anos recentes nos países citados sejam animadores, as conclusões não podem ser corroboradas pelos achados. As conclusões do capítulo sugeriram que uma comunidade profissional ativa pode afetar o estilo de vida e de consumo dos seus pares. Contudo, trata-se de uma análise descritiva de tendência. Sabe-se apenas que houve declínio no uso de tabaco, mas não é possível compreender, com base na leitura do capítulo, quais são as histórias de sucesso e como tais histórias se desenrolaram.

O Capítulo 6 (Discussion and conclusions) finaliza indicando que há desafios comuns para os países analisados nos quais as taxas de tabagismo permanecem elevadas. Os autores destacam que as especificidades dos vários povos dificultam a adoção de soluções genéricas e, revisitam as questões relativas às taxas de respostas - que, quando baixas, podem conduzir a um viés de representatividade da população alvo - e a falta de consenso na definição de fumante. Convidam ainda à reflexão sobre até que ponto o hábito tabágico pode ser diminuído com intervenções pontuais, ou se seria um sinal de problemas mais fundamentais ligados à profissão da saúde.
Antes do Apendix 3, das informações dos autores e das referências, nos Appendices 1 e 2 encontram-se revisões da escassa literatura existente sobre tabagismo entre médicos veterinários e estudantes de medicina veterinária, o que revela o compromisso em tentar abranger o tema entre os variados profissionais da saúde.

Acrescentamos que as estratégias de combate ao tabagismo vêm se mostrando bem sucedidas em diferentes países, mas muitas vezes geram estigmatização do fumante, o que desencoraja a busca de tratamento especializado. Na prática, parece haver tentativas de usar o estigma como ferramenta explícita para substituir a proibição, buscando por meio da culpa e da vergonha mudanças de comportamento (BELL et al., 2010).

Não foi intenção dos autores do livro, nem das autoras desta resenha, discutir as dimensões éticas e morais da estigmatização enquanto estratégia de saúde pública, mas tendo em foco a problemática do trabalhador da saúde que fuma, não é absurdo suspeitar que percebendo o estigma, tenda a manter em segredo o hábito e a se sentir inibido na procura a ajuda especializada.

Por fim, o alto percentual de fumantes entre trabalhadores da saúde com nível de graduação, apontado no livro, chama atenção para o fato da escolaridade e o acesso à informação sobre os riscos não operar neste segmento como fatores de dissuasão e abandono do hábito. Em que medida as condições de trabalho, penosas na área de saúde em vários países do mundo, com longas jornadas, contratos precários, trabalho noturno e em rodízio de turnos, alta carga de responsabilidade, ambientes insalubres e inadequados, exposição à violência e outros riscos não estariam associadas à persistência de um hábito? Em que medida a inexistência de políticas públicas robustas de combate ao tabagismo em alguns países estudados e a alta tolerância social ao hábito não interfere no comportamento dos profissionais de saúde? Essas são questões que que constituem bons temas para estudos futuros.

\section{Referências}

AZNAR, F. D. C.; PERES, S. H. C. S.; PERES, A. S. A atuação da Odontologia do Trabalho frente ao tabagismo nas empresas. Odonto, São Paulo, v. 20, n. 39, p. 123-129, 2012.

BARBEAU, E. M.; KRIEGER, N.; SOOBADER, M.; Working class matters: socioeconomics disadvantage, race/ethinicity, gender and smoking in NHIS 2000. American Journal of Public Health, v. 94, n. 2, p. 269278, 2004.
BAYER, R; STUBER, J. Tobacco control, stigma, and public health: rethinking the relations. American Journal of Public Health, v.96, n.1, p. 47-50, 2006.

BELL, K. et al. Smoking, stigma and tobaco 'denormalization': further reflections on the use of stigma as a public health tool. A commentary on Social Science \& Medicine's Stigma, Prejudice, Discrimination and Health Special Issue (67:3). Social Science \& Medicine, v.70, n. 6, p .795-799, 2010 
BRASIL. Ministério da Saúde. Brasil avança no combate ao tabagismo, 2011. Disponível em: http:// portal.saude.gov.br/portal/aplicacoes/noticias/default. cfm?pg $=$ dspDetalheNoticia\&id_area $=124 \& C O$ NOTICIA =12457. Acesso em: 14 jun. 2013.

CATTARUZZA, M. S.; WEST, R. Why do doctors and medical students smoke when they must know how harmful it is?. European Journal of Public Health, v. 23, n. 2, p. 188-189, 2013.

EZZATI M.; LOPEZ A. D.; Estimates of global mortality attributable to smoking in 2000. The Lancet, v. 362, n. 9387, p. 847-852, 2003.

GIATTI, L., BARRETO, S. M. Tabagismo, situação no mercado de trabalho e gênero: análise da PNAD 2008. Cadernos de Saúde Pública, Rio de Janeiro, v. 27, n. 6, p. 1132-1142, 2011.

IGLESIAS, R. et al. Controle do Tabagismo no Brasil. Washington: Banco Internacional para Reconstrução e Desenvolvimento/Banco Mundial. 2007. Disponível em: http://portal.saude.gov.br/portal/arquivos/pdf/
Controle\%20do\%20Tabagismo\%20no\%20Brasil.pdf. Acesso em: 14 jun. 2013

INSTITUTO NACIONAL DE CÂNCER. Inquérito domiciliar sobre comportamentos de risco e morbidade referida de doenças e agravos não transmissíveis: Brasil, 15 capitais e Distrito Federal, 2002-2003. Rio de Janeiro: Instituto Nacional de Câncer; 2004.

MAECKELBERGHE E.L.M. Doctors and medical students as non-smoking role models? Using the right arguments. European Journal of Public Health, v.23, n.2, p.190-192, 2013.

MONTEIRO, C. A. et al. Population-based evidence of a strong decline in the prevalence of smokers in Brazil (1989-2003). Bulletin of The World Health Organization, v. 85, n. 7, p. 527-534, 2007.

SZKLO, A.S.; SAMPAIO, M.M.A.; FERNANDES, E.M., ALMEIDA, L.M. Perfil de consumo de outros produtos de tabaco fumado entre estudantes de três cidades brasileiras: há motivo de preocupação?. Cadernos de Saúde Pública, Rio de Janeiro, v. 27, n. 11, p. 2271-2275, 2011.

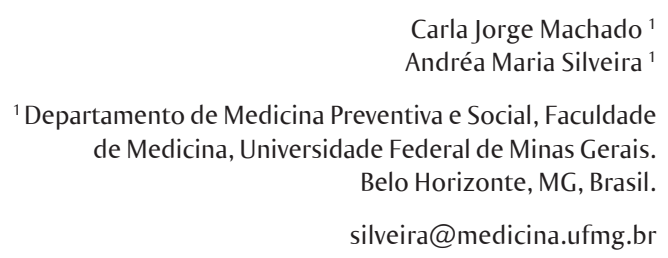

